\title{
El discurso civilista en tiempos de la Gran Colombia*
}

Recibido: 11/12/2018 | Revisado: 26/03/2019 | Aceptado: 08/05/2019

DOI: 10.17230/co-herencia.16.31.5

\author{
Juan Carlos Chaparro Rodríguez ${ }^{* *}$ \\ juan.filosofia@gmail.com
}

Resumen Desde el momento en que se consumó la independencia de Colombia, y como efecto del legado militar que se heredó de la guerra, se generó una intensa discusión sobre los asuntos militares, y especialmente sobre el lugar y el papel que los uniformados debían ocupar y desempeñar en el marco del nuevo orden institucional. El desarrollo de ese debate no solo aparejó dicha discusión, sino que desembocó en la configuración de un ingenioso y persuasivo discurso civilista, en virtud del cual se intentó subordinar a los uniformados y cimentar el orden institucional de la república. Describir el contenido y alcance político de esos discursos y debates, a partir de lo que se publicó en algunos periódicos y documentos de la época; y dilucidar cómo influenciaron el curso de la vida política e institucional colombiana durante aquellos años, son los objetivos del presente artículo.

\section{Palabras clave:}

Colombia, independencia, república, civilidad, cuestión militar.

\section{The civilist discourse in times of the Gran Colombia}

\begin{abstract}
From the moment the independence of Colombia was formalized, and as a result of the military legacy inherited from the war, an intense discussion arose on military matters, particularly on the place armed forces should have and the role they had to play within the new institutional order. The development of this debate not only fostered this discussion, but also resulted in a cunning and compelling civilist discourse, by which an attempt was made to subordinate the army and to cement the institutional order of the republic. This paper aims to describe both the content and political scope of these discourses and debates, drawing upon the material published in some newspapers and documents of the time. It also aims to elucidate how they influenced the course of Colombian political and institutional life during those years.
\end{abstract}

\section{Keywords:}

Colombia, independence, republic, civility, military matter.
* El presente artículo se deriva de algunos planteamientos desarrollados en trabajos previos. Por ejemplo, ver Chaparro Rodríguez (2017).

* Doctor en historia, profesor Universidad $\mathrm{Na}$ cional de Colombia, sede Bogotá, Colombia. 


\section{La independencia y la situación militar}

A comienzos de la década de los veinte del siglo XIX, una cuestión importante unía a los principales líderes políticos y militares de la naciente república de Colombia ${ }^{1}$ y otra, muy intensa, parecía dividirlos. La consumación y consolidación de la independencia eran, por una parte, asunto en el que unos y otros estaban francamente comprometidos. Por estas, decía Bolívar, los patriotas neogranadinos y venezolanos habían empeñado sus vidas, sus bienes y su tranquilidad; y, aducía, debían estar unidos ya que sus adversarios estaban dispuestos a contener sus propósitos, llevando la contienda armada hasta sus últimas consecuencias. ${ }^{2}$ Por otra parte, y no obstante que para aquel momento la guerra de independencia no había finalizado, algunos juristas y publicistas ${ }^{3}$ empezaron a emitir sus reparos frente a la cuestión militar de la naciente república de Colombia, es decir, frente a la situación en la que se hallaban los cuerpos armados que se habían conformado en virtud de la guerra; frente a la concesión y regulación de los ascensos, fueros, sueldos, pensiones y compensaciones otorgadas a los uniformados; y, especialmente, frente a las aspiraciones económicas, políticas y burocráticas que, según se decía, los integrantes de esa fuerza armada pretendían obtener, a expensas de sus rangos castrenses y del posicionamiento político y corporativo que habían adquirido gracias a su participación en la guerra.

A su juicio, todos esos asuntos, y especialmente el protagónico papel que los militares habían asumido en los asuntos políticos del país, habían engendrado un nefando militarismo que amenazaba con socavar las bases sobre las cuales se erigía la república.

1 Este artículo se refiere a la república que formalmente se conformó en 1819, por iniciativa de Simón Bolívar, tras la unión de la Nueva Granada y Venezuela, a la que luego se unirían Ecuador y Panamá, y que pervivió hasta 1830. El nombre oficial de esa unión fue República de Colombia, de modo que la expresión "Gran Colombia" se usa con el simple propósito de indicar la denominación que informalmente se le dio con el fin de diferenciarla de la que luego fue la actual república.

2 Así lo expresó Bolívar en su famoso discurso ante el Congreso de Angostura a comienzos de 1819 , y de la misma forma continuó expresándolo en sus proclamas y misivas. Ver Jaramillo Uribe (2002).

3 De esta manera eran denominados los hombres que se dedicaban a publicar y debatir, a través de periódicos, pasquines y libelos, los más diversos temas de interés público. En tal sentido, más que informar, el publicista se ocupaba de emitir conceptos u opiniones sobre diversos temas de interés público. Al respecto ver los trabajos de Gilberto Loaiza Cano (2010) y Luis Horacio Botero Montoya (2014). 
No se trataba, en estricto sentido, de un conflicto librado entre militares y civiles por el hecho de que cada quien fuera tal, sino de una confrontación de posturas, tejida a efectos de los legados militares que la guerra de independencia le había dejado a la nueva república y, desde luego, también en virtud de los intereses económicos, burocráticos, sociales y políticos que tenían los protagonistas de esa discusión y de la ideología que esos hombres abrazaban y defendían. Pero ¿qué era lo que la guerra le había legado militarmente a la naciente república de Colombia? ¿En qué términos y con qué argumentos se promovió el debate que los uniformados y sus contradictores plantearon con respecto a ese y a otros tantos asuntos relacionados con la cuestión militar?

Pues bien, aunque los datos emitidos no eran completamente fiables, los primeros informes oficiales presentados por la Secretaría de Guerra de la república de Colombia indicaban que, a comienzos de la década de los veinte del siglo XIX, el país contaba con una voluminosa y desorganizada fuerza armada cuyo número de combatientes se aproximaba a los 24000 (Gaceta de Colombia, 1822; "Memoria del secretario de Estado", 1823). ${ }^{4}$ La situación, ciertamente, no tenía antecedentes en la historia del otrora virreinato de la Nueva Granada, ni en la de la anterior Capitanía de Venezuela. Ni acá ni allá había existido necesidad de formar una fuerza armada de tal envergadura, pero, dada la coyuntura política y militar que se vivía, allende y aquende la frontera, la guerra había obligado a incorporar a hombres de todas las edades y de todos los grupos y sectores sociales. Análogamente a lo que habían tenido que hacer los dirigentes del proceso independentista en otros lugares de la América hispánica, en la Nueva Granada y Venezuela se habían visto obligados a formar diversos cuerpos armados (ejércitos, milicias, fuerzas marítimas), con el fin de confrontar a sus adversarios.

La realización de esta empresa no fue fácil de consumar, como lo ha mostrado la historiografía que se ha producido sobre la materia ${ }^{5}$ y como lo indican los testimonios que nos legaron los protagonistas de esa historia. Según versiones emitidas por diversas fuentes de la época, tanto el

4 Según fuentes documentales e historiográficas, en años posteriores el ejército llegó a tener más de 30000 hombres en filas. Ver Bushnell (1985, p. 297).

5 Aunque no es el único, el trabajo de Clement Thibaud (2003) es uno de los más completos análisis realizados sobre la cuestión militar neogranadina y venezolana en tiempos de la independencia. 
reclutamiento de hombres y la formación de ejércitos y milicias, como la creación de una reglamentación adecuada y de una comandancia efectiva que los rigiera, fueron asuntos de compleja y difícil realización toda vez que, por una parte, la Nueva Granada no contaba con una tradición militar que, eventualmente, hubiera facilitado el acometimiento de dicha empresa; y, por otra, las vicisitudes políticas y económicas que signaron el proceso independentista hicieron que ese proyecto estuviera atravesado por todo tipo de adversidades.

Así, por ejemplo, aunque a los pocos días de haberse declarado la independencia la prensa capitalina celebraba que el pronto y entusiasta alistamiento de varios miles de hombres "de hábitos inocentes y sencillos", "acostumbrados á manejar el arado", "exercitados en los mas duros trabajos", "llenos de buena fé y de amor a la libertad", "conocedores de los campos, caminos, montañas y veredas", "diestros en el manejo del caballo" y "dispuestos a defender la independencia", había permitido conformar varios escuadrones y batallones de infantería y caballería con los cuales se le haría "la guerra a los tiranos" (Diario Político de Santafé, 1810b, p. 1); ${ }^{6}$ dicha celebración fue opacándose por la lamentable carencia fiscal y la inexperiencia militar en la que se hallaron esos mentados cuerpos armados.

Según lo indicaba Antonio Nariño (1765-1823) en 1811, tras haberse realizado la declaración de independencia, la Nueva Granada no contaba con los "fondos, [...] exércitos [y] Generales [que se requerían] [...] para arrostrar á tantos peligros como por diversos puntos [la] amenazan" (La Bagatela, 1811a, pp. 1-2). . Este, a juzgar por las apreciaciones y los balances que se hicieron y publicitaron tanto en Santafé como en otros lugares de la Nueva Granada (La Bagatela, 1812, pp. 1-2), fue el elemento predominante que signó el carácter y la situación en la que se hallaron los cuerpos armados que se conformaron durante los primeros años de la independencia. Dicha situación tendió a empeorar por las tensiones políticas que se generaron,

6 Similares apreciaciones se habían hecho en el Diario Político de Santafé (1810a, pp. 1-2), y de ese mismo carácter fueron los planteamientos realizados en la edición N. ${ }^{\circ} 34$ del mismo diario (1810c, p. 1).

7 Apreciaciones como esta hizo Nariño en otro artículo publicado en La Bagatela (1811b, pp. 1-2). 
a propósito de la fragmentación política e institucional que se vivió durante aquellos años.

Además de la carencia presupuestal, de la inexperiencia en materia militar y de la incapacidad para incorporar y mantener en filas a miles de hombres, el asunto empeoraba en la medida en que los dirigentes del proceso independentista se dividieron política y jurisdiccionalmente entre centralistas y federalistas. ${ }^{8}$ Esto, ciertamente, fue lo que señalaron diversos analistas al indicar y lamentar que, estando en una situación y en una época en que las circunstancias "exig[ían] la pronta organización de exércitos respetables, que [fueran] capaces de contener la furiosa rabia de los tiranos que por todas partes solicitan nuestra ruina para redoblar las cadenas de la esclavitud" (Década, 1814, p. 6), resultaba lamentable que "Las tropas que se reúnen para nuestra defensa llevan consigo los mismos vicios [de la fragmentación], exibiendo por lo mismo la funesta señal de su destrucción" (El Explorador, 1814, p. 5).

Pese a que la situación era adversa, los independentistas neogranadinos se las arreglaron para hacerle frente, y lograron conformar algunos cuerpos de milicia y ejército en Santafé, Cartagena, Pamplona, Popayán, Casanare, Antioquia y otras provincias. Si bien no se cuenta con datos fidedignos sobre la materia, la historiografía tradicional y contemporánea indica que, hacia 1815, la Nueva Granada llegó a contar con un pie de fuerza (reclutado generalmente de manera forzada) que osciló entre 5000 y 6000 hombres, mayoritariamente jóvenes, dedicados a los más diversos oficios, apertrechados con armas muy rudimentarias y comandados por una oficialidad que, aunque carente de conocimientos expeditos en las lides de la milicia y de la guerra, poco a poco fue cualificándose a efecto de las exigencias y de la experiencia generada por la misma contienda armada. ${ }^{9}$

Así pues, y a pesar de todas las adversidades que tal empresa les deparó, con esa fuerza armada los independentistas neogranadinos lograron enfrentar a las tropas realistas que se hallaban apostadas en el norte y sur de la Nueva Granada, y a las que posteriormente

8 Al respecto ver Rodrigo Llano Isaza (1999).

9 Ver Thibaud (2003). 
llegaron de la península bajo el mando del general Pablo Morillo. ${ }^{10}$ Empero, los embates generados por la guerra de reconquista, ${ }^{11}$ que el monarca Fernando VII inició desde 1815 con el ánimo de recuperar sus dominios en América, pusieron en jaque a los independentistas y los obligaron, en unión con sus pares venezolanos que también habían padecido las más duras derrotas, a reencauzar sus estrategias y a incorporar un número creciente de hombres a sus filas. ${ }^{12}$ En virtud de esto, entre 1817 y 1819, miles de hombres -incluyendo los que se vincularon a través de varias legiones extranjeras $-^{13}$ fueron incorporándose a las filas de los independentistas, y la guerra, después de varios años de haberse iniciado y desplegado, fue inclinándose en favor de estos últimos.

Bajo el liderazgo de Simón Bolívar, y de otros jefes militares que luego descollaron como generales y coroneles del ejército colombiano, esos miles de hombres que fueron llevados a los campos de batalla no solo lograron consumar la independencia y generar las condiciones para reinstaurar el orden político e institucional republicano, que formalmente se había pretendido establecer en 1810, sino que, correlativamente y por el efecto mismo de la guerra, desde entonces asumieron un singular protagonismo político y social. Este, en efecto, fue el caso del general José Antonio Páez, aquilatado comandante de las tropas independentistas que se organizaron en los llanos venezolanos; y esa misma fue la pretensión que tuvieron los hermanos Monagas, que también organizaron tropas en el oriente de ese país, lo mismo que de otros uniformados que, como el propio Bolívar, consideraban que estos hombres debían tener un protagónico desempeño en la organización de la naciente república. ${ }^{14}$

A juicio de Bolívar, por ejemplo, los militares no solo debían gozar de la mayor consideración por el hecho de que ellos eran quienes le habían dado patria y libertad a sus hermanos sino porque, indudablemente, eran "el alma misma de la nación"15, ya que en el ejército, como en ninguna

$10 \mathrm{Al}$ respecto ver Mercado, $\mathrm{J}$.

11 Llamada también guerra de restauración por el historiador Daniel Gutiérrez (2016).

12 Para detalles precisos de ese proceso ver Daniel Gutiérrez Ardila (2016), Rebecca A. Earle (2014) y Michael P. Costeloe (2010).

13 Ver Matthew Brown (2010).

14 Ver Juan José Conde (1842).

15 Así lo expresó Bolívar en una carta dirigida al general Santander en vísperas de la batalla de Carabobo en junio de 1821. Ver Giuseppe Cacciatore y Antonio Scocozza (2010, pp. 235-236). 
otra institución, se había logrado congregar y hermanar a esa pluralidad de hombres que habitaban en los más diversos y remotos pueblos y lugares que conformaban la Nueva Granada y Venezuela, y que ahora, tras casi una década de guerra y sin que la independencia se hubiera consumado, se disponían a formar un solo cuerpo político llamado la república de Colombia.

Esto, ciertamente, fue lo que argumentó Bolívar en muchas de sus misivas y proclamas, y de ello dio explícito testimonio en una famosa carta enviada al general Francisco de Paula Santander arguyendo que, contrario a la representación y a la vocería política que los letrados, abogados y juristas neogranadinos pretendían asumir en cuanto a los asuntos públicos de la naciente república de Colombia, ellos debían persuadirse de que la genuina y autentica representación popular se hallaba encarnada en el ejército, pues era en este en donde realmente se había congregado ese pueblo, que aún pugnaba y luchaba por liberarse de la tiranía española que durante siglos lo había dominado:

Esos señores piensan que la voluntad del pueblo es la opinión de ellos, sin saber que en Colombia el pueblo está en el ejército, porque realmente está, y porque ha conquistado este pueblo de manos de los tiranos; porque además es el pueblo que quiere, el pueblo que obra y el pueblo que puede; todo lo demás es gente que vegeta con más o menos malignidad, o con más o menos patriotismo, pero todos sin ningún derecho a ser otra cosa que ciudadanos pasivos (Cacciatore y Scocozza, 2010, pp. 235-236).

Las vicisitudes de la guerra y las realidades políticas que aparejó la independencia no solo habían conducido a que los militares construyeran y adquirieran un sofisticado protagonismo político y social, sino que determinaron que, al terminar la guerra, muchos militares fueran nombrados en diversos cargos de la administración pública estatal. Ya fuera en las gobernaciones, en las jefaturas políticas y militares, en las inspecciones de aduana, en los fuertes militares, en las secretarías de gobierno, y en otras tantas dependencias que ahora componían el Estado colombiano, muchos militares fueron destinados a ellas para que cumplieran labores para las que, en muchos casos, no había quién las realizara. 
Empero, no pasó mucho tiempo para que tal estado de cosas fuera puesto en abierta y virulenta discusión, por parte de quienes buscaron relegarlos de la vida político-administrativa del Estado y desvirtuar los imaginarios que aquellos habían construido sobre sí mismos. Esta, en efecto, fue la tarea que acometieron hombres como Vicente Azuero (1787-1844), Florentino González (1805-1874), Francisco Soto (1789-1846) y otros tantos que, escribiendo abierta o anónimamente en periódicos y pasquines, o debatiendo desde el seno del Congreso de la república, no solo promovieron las reformas que, a su juicio, debían imprimírsele a los cuerpos armados que la guerra le había legado, sino que elaboraron y publicitaron un sofisticado y radical discurso antimilitarista que traería consecuencias definitivas para el destino inmediato de la república y para el de la misma fuerza armada estatal.

\section{Génesis y proyección del discurso antimilitarista}

La discusión sobre la cuestión militar empezó a gestarse y publicitarse desde los primeros años de la década de los veinte del siglo XIX. A tal efecto, las páginas de El Patriota, La Indicación, La Miscelánea, El Cachaco, la propia Gaceta de Colombia, y de otros tantos pasquines, panfletos y hojas sueltas que editaron, publicaron e hicieron circular durante aquellos años, se convirtieron en el expedito medio a través del cual Azuero, González, Soto, Santander y otros tantos hombres que fungían como publicistas expusieron sus ideas y presentaron los propósitos que tenían con respecto a la cuestión militar. Denunciar las nocivas consecuencias que las acciones y pasiones de los caudillos y jefes militares generaban para la consolidación y estabilización del orden republicano, y rechazar las ambiciones políticas, burocráticas y estamentales que aquellos detentaban o ambicionaban, aduciendo que ellas constituían la más infame amenaza para la consumación de la libertad, fue la consigna que aquellos hombres enarbolaron durante aquellos años. ${ }^{16}$

Así, por ejemplo, y luego de que se asegurara la derrota de los españoles en suelo colombiano, el jurista Vicente Azuero argumentaba que ya no era necesario seguir manteniendo en servicio activo

16 Esos, ciertamente, fueron los términos y las consideraciones que aquellos hombres establecieron para llevar a cabo su tarea, y así lo dejaron establecido en los Prospectos de sus periódicos y pasquines. 
a una fuerza armada tan voluminosa que solamente servía para malgastar los escasos recursos con que contaba el Estado, y para mantener y proyectar el espíritu militarista que había germinado entre los militares, por efecto del autoproclamado heroísmo con que estos habían afrontado la guerra; por la desmedida concesión de ascensos que se les había otorgado durante y después de esa guerra; por la poca institucionalización que tenían los distintos cuerpos armados que se habían conformado; y por las exigencias que sus integrantes empezaban a hacer en materia de sueldos, pensiones y compensaciones. ${ }^{17}$

Argumentos, decía Azuero, no faltaban para promover la pronta y efectiva reducción, y si acaso abolición del ejército y de los demás cuerpos armados (milicia y marina) que la guerra había obligado a conformar. Además de haberse constituido en un notorio problema en razón de su propio tamaño, Azuero afirmaba que esos cuerpos, y particularmente el ejército, se habían convertido en una fuente de amenazas para la estabilidad y proyección de la naciente república ya que, por una parte, muchos de los hombres que aún mantenían las armas en sus manos no parecían actuar a efectos de las instancias y mandatos institucionales que debían regirlos, sino en virtud de los lazos de compadrazgo y camaradería que los unían a sus respectivos jefes y caudillos. Esta situación, decía el citado publicista, era una genuina causa de preocupación para quienes consideraban que la imposición de un gobierno de facto, contrario al espíritu y a los propósitos de la república, podía ser facilitado, y hasta instigado, por los jefes y caudillos militares que quisieran hacerlo valiéndose de esa masa de hombres armados que mantenían bajo su dominio.

Por otra, y a efecto de las reclamaciones y exigencias que los militares habían empezado a realizar amparándose en lo que el propio "Libertador" les había ofrecido para que se vincularan a los diversos cuerpos armados que se constituyeron a raíz de la guerra, ${ }^{18}$ se aducía que dicha situación justificaba aún más la eventual abolición de dichos cuerpos, ya que su existencia estaba expoliando las exiguas rentas con que contaba el naciente Estado colombiano. Razones

17 Los primeros planteamientos que Vicente Azuero realizó con respecto a la cuestión militar fueron publicados en varios números de su periódico La Indicación en 1822 . La versión completa del documento fue publicada bajo el título La propuesta federal.

18 Sobre las compensaciones prometidas a los militares, ver el decreto expedido por Bolívar citado por Federico Brito Figueroa (1966, p. 207). 
como estas tampoco parecían faltarles a los escrutadores de la cuestión militar, pues era cierto que desde aquel temprano momento de vida independiente, el voluminoso grupo de generales, coroneles, sargentos mayores, capitanes, tenientes, cabos y soldados que integraban los distintos cuerpos armados de la república, estaban empezando a reclamar, muchas veces de manera irregular e incontrolada, sueldos, pensiones y otras prerrogativas que se les había prometido por sus servicios en la guerra.

Según indicaban los detractores de dicha situación, además de las solicitudes de pago presentadas por los militares, y justamente porque no había mayor claridad sobre la legalidad de esas exigencias, el ramo militar se había convertido en uno de los principales focos de expoliación del tesoro público. Tan sintomático era el asunto que hasta el propio secretario de Guerra y Marina, general Pedro Briceño Méndez, se encargó de denunciar la cuestión al indicar que, en ausencia de un efectivo mecanismo de control administrativo, cada vez se hacía más notoria la innoble conducta con que muchos militares actuaban para desfalcar el tesoro público, ya porque se hacían pagar sueldos o indemnizaciones indebidamente, o bien porque algunos jefes desviaban los recursos que se les asignaba para solventar las necesidades de las tropas que tenían a su cargo ("Memoria del secretario de Estado", 1823, p. 4).

Al conocer de tales situaciones, y mientras que los legisladores trabajaban para remediarlas creando y expidiendo una voluminosa serie de leyes a través de la cual pretendieron reglamentar y regular los más diversos aspectos que se relacionaban con la cuestión militar, y especialmente con los que referían a la organización, misiones y limitaciones asignadas e impuestas al ejército, la milicia y la marina, ${ }^{19}$ sus copartidarios militarismo que se había desplegado en la república, fomentaron una persuasiva campaña mediática con el propósito de vindicar el subordinado y apolítico lugar que los militares debían ocupar y desempeñar en el marco del nuevo orden institucional; de denunciar los riesgos y peligros que el mentado militarismo aparejaba para la república; y de contener el ascenso político y burocrático

19 Las mentadas leyes orgánicas de ejército, milicia y marina fueron creadas y sancionadas durante la legislatura de 1826. Ver Gaceta de Colombia (1826a, pp. 5-6), Gaceta de Colombia (1826b, pp. 5-8) y Gaceta de Colombia (1826c, pp. 1-2). 
que, a su parecer, los uniformados, o por lo menos sus más reputados generales, pretendían alcanzar a costa de los ciudadanos y en contra del bien común.

A tal efecto, y persuadidos de que su proyecto debía tener la máxima difusión pública, y buscar los máximos apoyos políticos y sociales posibles, aquellos hombres no solo recurrieron a la prensa, a los estrados del parlamento y a los demás medios y espacios públicos que tuvieron a su disposición para divulgarlo, sino que buscaron validarlo, presentándolo como un asunto de interés colectivo y nacional, vindicando que "la libertad de imprenta esta[ba] sancionada en [el] país, del modo estenso que ella demanda[ba]", y destacando que por ese motivo y a través de ese medio "todos sus habitantes está[ban] llamados á intervenir" y a participar en las discusiones de interés público y político (Gaceta de Colombia, 1830a, p. 4). Los detractores del mentado militarismo emprendieron su tarea y propendieron por la legitimación y consumación de su proyecto.

En tal virtud, y convencidos de que su propósito y discurso debían ser lo suficientemente persuasivos para poder ganar el mayor número de adeptos, los detractores del militarismo adujeron, con creativa y desbordada retórica, que su deseo y objetivo de contener esa situación no era cosa que obedeciera a un simple capricho, sino que obedecía a la sagrada misión que como ciudadanos debían acometer con el sublime y elevado propósito de salvaguardar la república y la libertad por las que tan caro habían pagado los pueblos. A su juicio, estas solo tendrían posibilidad de subsistir y proyectarse si se lograba protegerlas del militarismo que amenazaba con expandirse en el país.

Aunque retóricas, sus apreciaciones no carecían de sentido y contenido. La libertad fue enarbolada y defendida como un bien supremo que cobraba valor por sí misma, y cosa similar se hizo con la noción de república. Resignificada teórica, jurídica, ideológica y políticamente, esta no solo había adquirido nuevos contenidos y significados en aquel contexto de crisis y transición política, ${ }^{20}$ sino que se había convertido en el referente político por excelencia, a partir del cual se buscó sentar y legitimar el nuevo orden institucional.

20 Crisis de la monarquía y del Antiguo Régimen, e independencia y transición hacia el orden republicano. 
En efecto, según se indicaba en las diversas declaraciones expresadas por los hombres que en aquella época se pronunciaban sobre el tema, la idea de república ya no refería, como ocurría en el lenguaje político del Antiguo Régimen, al conjunto de individuos que integraban los gremios económicos, las corporaciones urbanas o el espacio territorial (villa, ciudad, reino, etc.) sobre el cual se asentaban determinados grupos sociales ${ }^{21}$ sino que ahora refería, en una acepción moderna dotada de nuevos contenidos y concebida fundamentalmente por oposición al carácter injusto, despótico y autoritario del régimen monárquico, a una particular forma de gobierno fundamentada en la ley, en el acatamiento de esta por parte de todos los pobladores y ciudadanos; en la soberanía popular, en la delegación y representación del poder político; en la limitación, control y equilibrio de los poderes públicos; en la promoción y fomento de una opinión pública vigilante y responsable; en la igualdad legal entre los individuos; en la oposición a las distinciones sociales generadas por títulos y fueros estamentales; y en la adopción, tanto individual como colectiva, de una conducta ética (ethos cívico) que relevara la trascendencia de la libertad, la igualdad, la seguridad y la propiedad a las que formalmente tenían derecho todos los miembros de la comunidad política. ${ }^{22}$

La idea de república no solo se convirtió en el predominante arquetipo político a partir del cual aquellos hombres elaboraron y defendieron sus concepciones sobre el carácter político, institucional y jurídico que debía asumir el nuevo orden estatal, sino que fue a partir de ella que fomentaron la subordinación y proscripción política y burocrática de los militares. A su juicio, estos debían asumir y mantener la más irrestricta subordinación frente a la majestad de las leyes, de las instituciones y de las autoridades que le daban forma a la república; y asumirse, irrecusablemente, como el brazo armado con que aquella contaba para su defensa y protección, pero en modo alguno para su gobierno:

21 Sobre la discusión teórica y política que el citado concepto tuvo durante aquellos años, ver Lomné (2009, pp. 1253-1269).

22 Sobre el contenido, el carácter y el alcance político que la idea de república (y el ideario republicano en su conjunto) empezó a tener en Hispanoamérica desde tiempo de la independencia, ver Sábato (2008). 
La constitución de Colombia [dijeron] ha abolido el gobierno militar, ventaja preciosa e inestimable, que excitará siempre la gratitud de los pueblos por sus sabios institutores. Gobierno militar, idea extravagante y necia, especie de mostro que abortó la Iberia, y que lleva impresos todos los caracteres de la crueldad, del orgullo y de la barbarie española. El capricho de los militares sostenido por el aparato de la fuerza y por el imperio de las circunstancias, tal es la ley fundamental, tal el principio de acción bajo de este nuevo sistema de conducir y gobernar á los hombres. Las leyes callan en presencia de la clase que manda, y el hombre de bien, separa sus ojos por no ver el cúmulo de injusticias, de desórdenes y atrocidades, que ejecuta por todas partes el sable y el fusil.

Este sistema, ó forma de gobierno (si es que se le puede dar estos nombres) es una tiranía de alto género, es mas despotico, mas arbitrario, mas injusto é inicuo, que el monárquico absoluto [...]. El menor de los soldados egerce donde quiera que se halle la plenitud del poder, y se ha visto con asombro á toda la masa de un pueblo obedecer sumisamente al antojo y apetitos extravagantes de un solo militar [...]. El gobierno militar desconoce la división de poderes, la soberanía del pueblo, los trámites legales de la administración de justicia, y todo cuanto en él se practica lleva consigo el carácter de la violencia y de la arbitrariedad (El eco de Antioquia, 1822, pp. $3-4) \cdot{ }^{23}$

Al exaltar la majestad de la Constitución política, de las leyes y de la soberanía popular, oponiéndolas a la señalada naturaleza autoritaria y despótica del régimen monárquico español, y al asimilar la injerencia política de los militares a ese régimen, los antimilitaristas no dejaban lugar a dudas: en lo sucesivo recurrirían a todo lo que les fuera posible, a todo lo que su ingenio les permitiera, y a todo lo que su punzante pluma les permitiera escribir, para proscribir a los militares y para desvirtuar sus pretensiones. Además de persuasivas, las disertaciones que aquellos hombres elaboraron y publicitaron, fueron

23 Este artículo fue reproducido bajo el mismo título en el Correo de la ciudad de Bogotá (1822b, p. 1), periódico de cuya redacción se ocupaban Francisco de Paula Santander, Vicente Azuero y Francisco Soto. Se publicó en dos partes, la primera de ellas en el número inmediatamente anterior a este, es decir, el del 20 de junio de 1822, bajo el título "Sentimiento de un ciudadano a favor de la forma de gobierno de Colombia". 
ingeniosas. Ciertas o no, eso poco les importaba. Lo fundamental, según se colige de sus escritos y de sus propósitos, era desvirtuar los intereses políticos y burocráticos de esa cantidad de generales, jefes y caudillos militares hornada de generales, jefes y caudillos militares que habían surgido de la guerra de independencia y que, según decían, buscaban publicitar sus proezas militares para apalancar y legitimar su deseo de hacerse con el gobierno del Estado, y para obtener sueldos, pensiones, indemnizaciones, ascensos y fueros, así estos no estuvieran legalmente justificados.

Invocando los axiomas políticos y filosóficos del ideario republicano y liberal que se popularizó con tanta fuerza en aquel entonces; ${ }^{24}$ emulando, o tratando de emular, las medidas que algunos gobernantes europeos habían implementado durante el siglo XVIII (y en muchos casos desde antes), con el propósito de garantizar la subordinación militar y la definición de los específicos ámbitos de acción y jurisdicción que debían tener los uniformados; y, echando mano de las diversas medidas y reformas que la Corona española había tomado en materia de organización militar durante las últimas décadas del periodo colonial, ${ }^{25}$ los antimilitaristas publicitaron todo tipo de ideas, reflexiones y propuestas relacionadas con la disminución del ejército, con su reemplazo por una guardia de carácter eminentemente cívico, con la restricción de la injerencia que los militares pudieran tener en asuntos políticos que no eran de su facultad, y con la neutralización de sus posibilidades para instaurar un gobierno militar o para perpetrar un golpe de Estado.

En tal virtud, y aunque no era la primera vez que en el país se publicitaba ese tipo de ideas y propuestas, ${ }^{26}$ en esta ocasión, y amparados en la noción de civilidad que ellos mismos se encargaron de

24 Respecto del sentido que esos términos fueron adquiriendo en los casos neogranadino y venezolano, ver Calderón y Villamizar (2009, pp. 771-781) y Leal, Guerrero y Plaza (2009, pp. 837-845).

25 De manera especial, las Ordenanzas de S.M. para el régimen, disciplina, subordinación y servicios de sus ejércitos (1768). Ver Kuethe (1993) y Blanco Valdés (1988).

26 En tiempos de la primera república, el jurista neogranadino Miguel de Pombo (1779. 1816) había enfatizado sobre la necesidad de promover una pedagogía cívica orientada a hacer del soldado un ciudadano, antes que un guerrero. Al respecto, ver Clément Thibaud (2012, pp. 318-319). 
publicitar, ${ }^{27}$ los antimilitaristas fueron más incisivos en su apuesta por consumar sus propósitos. Actuando con el ingenio y la perspicacia que el asunto les demandaba, buscaron convencer a los militares de que su legal y natural condición no solo era la de mantenerse subordinados, obedientes y no deliberantes ante el Estado y las autoridades civiles instituidas, sino la de constituirse y concebirse como genuinos defensores de la república:

Los defensores de la independencia y libertad de Colombia deben hacer los votos más firmes por tales objetivos [...]. Amor á la independencia y á la libertad, respeto y obediencia á las leyes, y á las autoridades, sumisión á sus superiores, valor, constancia y sufrimiento he aquí en compendio las virtudes que deben adornar á un militar como defensor de la república. Los pueblos extranjeros pueden venir á admirar en los bravos militares de Colombia virtudes poco comunes, y el orgullo de estos defensores ilustres debe consistir no solo en lo que ya han trabajado por libertar á su patria del yugo español, sino en lo que tienen aún que trabajar constantemente en mantenerla independiente y bajo el dulce imperio de las leyes (El Patriota, 1823, pp. 2-3).

Pero si de ese talante fueron las consideraciones emitidas por los detractores del mentado militarismo, que supuestamente anidaba entre los uniformados, de similar factura fueron los argumentos que expresaron los simpatizantes y defensores de los militares. Defender y loar el honor de los militares; exaltar los sacrificios que estos habían hecho en procura de alcanzar la independencia; aclamar su papel como formadores y protectores de la república; y vindicar lo que por justo derecho merecían fue, en efecto, la base de los argumentos a partir de la cual los militares y sus simpatizantes pronunciaron en defensa de sus intereses y concepciones políticas y corporativas.

Aduciendo que los uniformados no eran autómatas, faltos de conciencia política o carentes de criterio propio, como para ponerse al servicio de los caprichos y de la voluntad de cualquier individuo sin detenerse a pensar qué era lo conveniente y qué era lo perjudicial para la república, los militares y sus simpatizantes argumentaron que los jefes y comandantes militares no solo sabían de la responsabilidad que les correspondía asumir para defender y mantener el orden republicano, sino

27 Sobre el contenido y los alcances de esas ideas, ver Hensel Riveros (2006). 
que siempre habían dado genuinas y suficientes muestras de entrega y sacrificio por la patria y la república:

La milicia colombiana, no es la milicia de las monarquías; aquí el soldado debe saber (y lo saben muchos) cual es la causa por la que se lleva al combate, y en cuanto a sus gefes no es orgullo ni vanidad asegurar que conocen sus derechos y los de su patria [...] y [i] acaso han dado más pruebas de que los aman [?] (Correo de la ciudad de Bogotá, 1822a, pp. 1-2). ${ }^{28}$

Argumentos y contraargumentos de variada factura fueron elaborados y expuestos por cada quien durante aquellos primeros años de vida independiente. Si locuaces se mostraban los antimilitaristas, vehementes y persuasivos se mostraban también los militares y sus simpatizantes, al momento de defender y garantizar sus ideas, su honor y sus intereses, aduciendo, entre otras cosas, que antes de ser militares, ellos eran ciudadanos, acreedores de los mismos derechos que tenían quienes buscaban proscribirlos. En tal virtud decían y vindicaban que si alguno de ellos detentaba determinado cargo público, los demás ciudadanos debían tener en cuenta que esto obedecía a las virtudes personales, al amor patrio y al desinterés personal que los caracterizaba, y no al supuesto favorecimiento que se les hacía por el hecho de ser militares:

El ejército ha logrado destruir las masas españolas que trataban de conservar este país bajo su dependencia, ha visto con mucho gusto constituirse un gobierno popular representativo cuya principal base es la igualdad legal, pero debe observar con bastante desagrado, la oposición de cierta clase á sus gefes; estos nunca han tratado de hacerse superiores á sus conciudadanos, pero tampoco permitirán que se les degrade, ni que se les prive maliciosamente del goce de los bienes de la libertad con los demás hijos de Colombia [...].

[Los militares] Son acreedores, por consiguiente, a la gratitud pública, y no á que los desprecien ni que indirectamente les echen en cara su colocación actual; si ellos no fueran obedientes no serían empleados porque sus sentimientos están en oposición con los mandos civiles; de parte del congreso, del gobierno han

28 Cuarta carta á D. Candido Justo Veritas. 
merecido gratitud, respetos y aplausos: ipor que los periodistas y ciertos hombres ingratos los han de saerir y atribuirles otras miras? Demonos todos el tratamiento que mutuamente nos debemos y unámonos para bien de la patria y seamos siempre justos. J. M. C. (Correo de la ciudad de Bogotá, 1823, p. 3).

Declarando ser tan o más republicanos y patriotas que sus adversarios, los militares no se arredraron cuando tuvieron y quisieron contestar los ataques y señalamientos que se les hacían. En consecuencia, con tal situación, y dado el encono que distanciaba a esos hombres, ni la unión ni el justo trato que cada quien reclamaba fue lo que reinó en el país durante aquellos años. Las declaraciones y argumentaciones expresadas por los militares y por sus detractores daban cuenta de la rauda pugnacidad que se había generado entre unos hombres que se concebían y reclamaban como gestores de la independencia, protectores de la república y guardianes de la libertad, y otros que se consideraban faros y guardianes de la moral, de la civilidad y de los asuntos públicos y que, por tal motivo, se veían y asumían como los legítimos e idóneos regentes del nuevo orden.

Desvirtuar a su contrario fue el objetivo que cada quien se trazó, en aquel momento en que la definición de lo civil y lo militar apenas empezaba a delinearse, y en el que, por demás, aumentaban las rencillas que existían entre los abogados y burócratas neogranadinos y los militares y caudillos, mayoritariamente venezolanos. Convencidos y empeñados en defender sus respectivos propósitos, unos y otros no dudaron en hacer lo que consideraron pertinente con tal de lograr su cometido, y explotar las ventajas y situaciones que fueran favorables a sus intereses.

Aun cuando los militares nunca se pronunciaron ni actuaron de manera unificada, sus detractores no solo se mostraban vigilantes y escrutadores de sus conductas, sino que, mediática y estratégicamente, tendieron a mostrarlas como si se tratara de actos realizados por y en nombre de todo el estamento militar.

Esta fue la idea y la imagen que proyectaron los antimilitaristas desde los primeros años de la década de los veinte y, ciertamente, la que reforzaron desde que se presentaron algunos hechos en los que jefes y oficiales del ejército colombiano se vieron comprometidos, como se verá a continuación. 


\section{El afianzamiento y las consecuencias del debate}

Los hechos acaecidos durante la segunda mitad de la década de los años veinte del siglo XIX, y en los cuales algunos militares se vieron involucrados, radicalizaron la postura antimilitarista que Azuero, González, Soto y sus copartidarios habían promovido en el país. En abril de 1825, por ejemplo, estos fueron implacables frente a la conducta que había asumido un oficial venezolano, el coronel Leonardo Infante, quien fue sindicado, enjuiciado y condenado a muerte por, supuestamente, haber perpetrado un asesinato. A partir de ese hecho, promovieron un virulento debate público mediante el cual buscaron avivar el sentimiento y la opinión antimilitarista. Luego de ejecutar la sentencia que la justicia había proferido en contra de Infante, e incluso en el mismo acto de su consumación, el General Santander, alentado por sus copartidarios y por las rencillas personales que él había tejido con el sentenciado, se encargó de arengar a viva voz y en plaza pública contra la conducta asumida por el coronel Infante, advirtiendo que en Colombia no había lugar para ningún acto de insubordinación militar (Gaceta de Colombia, 1825, p. 1).

Tras promover y ejecutar una sentencia de tales características y magnitud, los civilistas creían que, en delante, nada ni nadie detendría su empresa, y así pretendieron ratificarlo un año después cuando el general José Antonio Páez, venezolano como Infante, procedió a reclutar hombres para la milicia sin contar con el aval de las autoridades. Ante el debate público que los antimilitaristas generaron en Bogotá, la Cámara de Representantes decidió llamar a indagatoria al general Páez. Este, que no era un hombre que se arredrara ante ese tipo de situaciones, no solo contestó que no acudiría a ese llamado, sino que respondió con una sonora advertencia indicando "que a un hombre como él le valían más las armas que las leyes" (Gaceta de Colombia, 1826d, p. 2). ${ }^{29}$

Al calificarla y exponerla mediáticamente como una rebelión, los antimilitaristas, neogranadinos en su mayoría, se mostraron enfáticos y determinados contra la conducta que había asumido el general Páez (Gaceta de Colombia, 1826d, p. 2), pero no prosperaron en su propósito, esto es, en hacer que Páez fuera enjuiciado y eventualmen-

29 Gaceta de Colombia № 247 [Bogotá] jul. 9, 1826: 2. 
te condenado. A lo sumo, e intentando ganar adeptos para su causa, indicaron que la infamante actuación que ese caudillo había asumido en compañía de otros jefes militares hacía "necesario un esfuerzo simultáneo de todos los colombianos para cortar el mal en sus principios" (La Bandera Tricolor, 1826a, p. 3), ${ }^{30}$ con el fin de garantizar que la república se afianzara y proyectara libre de esas montoneras que surgían de los cuarteles y que acaudillaban hombres como Páez.

Análogamente a lo que habían expresado desde hacía mucho tiempo, en esta ocasión adujeron que la fuente de los males que padecía la república se hallaba en el abultado ejército que se mantenía en servicio activo sin que hubiera necesidad ni justificación para ello; en la preferencia con que el general Bolívar trataba y protegía a los militares; en el afianzamiento del espíritu militarista que anidaba y campeaba entre los uniformados; en el hecho de que estos creyeran que su participación en la guerra de independencia los había hecho superiores a los demás ciudadanos; y en las ansias de poder político que tenían algunos jefes militares. ${ }^{31}$

En consecuencia con esto, y como prueba de que estaban dispuestos a llevar su empresa hasta el final, aquellos hombres se enfrentaron, abierta o soterradamente, al mismísimo "Libertador". Aduciendo que las insubordinaciones y los indebidos e irresponsables pronunciamientos políticos efectuados y proferidos por algunos jefes militares se habían originado por obra del pretensioso protagonismo que estos habían adquirido tras la consumación de la guerra de independencia, y por los caprichos y las pretensiones dictatoriales que Bolívar tenía, ${ }^{32}$ los autoproclamados civilistas buscaron hacerle un juicio público argumentando, o por lo menos sugiriendo, que ese militarismo con el que él cohonestaba era la causa fundamental que estaba minando las bases sobre las cuales se había erigido la república de Colombia (El Chasqui Bogotano, 1827, p. 1).

Era 1827 cuando esto se decía y los señalamientos y las sindicaciones antimilitaristas habían alcanzado niveles nunca antes vistos.

30 La Bandera Tricolor era un periódico editado y dirigido por Rufino José Cuervo quien, años más tarde, se alinearía en el Partido Conservador.

31 Así lo dejó testimoniado Florentino González (1975, p. 90).

32 Estas, según ellos, habían quedado expresadas en la Constitución política que el Libertador había creado para la recién creada república de Bolivia. 
Así como lo había expresado desde comienzos de 1820, en esta ocasión Azuero volvió a ser incisivo y categórico en sus apreciaciones y declaraciones. A su juicio, la pervivencia del ejército y las infundadas y arbitrarias pretensiones políticas y burocráticas de los militares contrariaban el espíritu civilista de la república y, peor que esto, auguraban su inminente destrucción:

\begin{abstract}
Al hablar de esta materia [dijo Azuero] nos es bien sensible tener que explanarnos en algunas circunstancias que han hecho demasiado horrorosa la situación de la República por consecuencia de la inmoralidad de una gran parte de la fuerza armada que sostiene aun en su seno. Desde que un estado se halla en el caso de constituirse y de asegurar por este medio la libertad, primer objeto, de la independencia debe ante todas cosas poner una valla que contenga en todas épocas el espíritu militar que ha debido apoderarse de una parte de sus ciudadanos acaso con perjuicio de la moral pública (El Zurriago, 1827, p. 1).
\end{abstract}

Como efecto del diagnóstico que los antimilitaristas elaboraron sobre las consecuencias que esa situación había generado para la república, estos no dudaron en proponer las soluciones. A su juicio, al promover y consumar la abolición del ejército, el Estado vería aliviado el tesoro público, y proyectaría el carácter civilista que habría de distinguirlo, pues se proscribiría el espíritu militarista que los caudillos y jefes militares habían sembrado en el país, y en virtud del cual pretendían regentar los destinos de la república. En esta, como en sus anteriores declaraciones, Azuero y sus copartidarios fueron concluyentes. Según sus criterios e intereses, las perentorias tareas que debían adelantar los legisladores colombianos tendrían que orientarse a proscribir a los militares de su injerencia en la política; subordinarlos a la autoridad y a la institucionalidad jurídica y estatal establecidas; y romper la odiosa obediencia militar que se fundaba en la filiación personal y corporativa pues esta, además de generar toda suerte de anarquías y desgracias públicas, imposibilitaba la construcción de una institucionalidad militar, si es que a esto, por desgracia, advertían y lamentaban, tenía que avenirse la república:

Qué esperanzas deben animar á un estado que ve que los hombres que ha armado en su defensa, y que sostiene con el fin de conservar 
sus derechos, se vuelven, y le dicen: "Nosotros no reconocemos las autoridades nacionales, no obedecemos las sanciones soberanas, sino solamente las que emanen de nuestro jefe, de un hombre a quien ciegamente nos sometemos, aun cuando sea con el fin detestable de esclavizar la República”! ¡Dios santo! A qué estado hemos llegado! Son los hombres y no las leyes las que deben rejir á un pueblo que ha peleado 17 años por conseguir su libertad, por no estar sujeto á voluntades pasajeras y caprichosas sino á la autoridad de las leyes siempre igual e impasible.

Estas y otras razones que después espondremos, son las que nos han autorizado a impugnar la permanencia del ejército que á la vez que amenaza la libertad, causa la aflicción del erario, y el descontento de los pueblos. No ha sido pues nuestro ánimo tocar en ridículas personalidades, sino hablar de los males que causa en general un ejército y unos cuerpos estranjeros que sin necesidad han venido á esta capital debiendo estacionarse en los puertos ó lugares en que no resida el gobierno y sean menos peligrosos, pues como dijimos en nuestro número anterior -Hay ciertas armas cuyo número prohive el derecho de jentes aún á las naciones que se hacen la guerra naturalmente y lo que son las armas prohibidas entre los pueblos, es la fuerza militar entre los gobernantes y gobernados- (El Zurriago, 1828, p. 1).

Elocuentes para sus copartidarios y demagógicas para sus adversarios fueron las declaraciones que los antimilitaristas profirieron por doquier durante aquellos años. Las páginas de sus periódicos recurrentemente se llenaban de tales consideraciones, lo propio pasaba con la prensa oficial, y con alguna prensa particular en la cual los militares y sus simpatizantes tuvieron posibilidad de expresar sus ideas y propósitos.

Además de vindicar la pervivencia del ejército aduciendo que este era el connatural instrumento que debía tener la república para garantizar su independencia y su libertad, los militares, y quienes se adherían a ellos, también reclamaron el derecho a mantener prerrogativas propias del estamento castrense (ascensos, fuero y justicia penal militar, etc.), ${ }^{33}$ y a pronunciarse sobre los asuntos políticos que les resultaban fundamentales para la conservación de la república. Ante los reparos y consideraciones

33 En otro artículo de mi autoría si han analizado los debates que, durante aquella época, se plantearon en torno al fuero militar. Ver Juan Carlos Chaparro Rodríguez (2010). 
que los antimilitaristas habían planteado con respecto a la abolición del fuero castrense y frente a la regulación del pago de sueldos y pensiones, ${ }^{34}$ los militares y sus voceros respondieron de manera terminante:

Ni mas ni menos les ha sucedido á VV señores militares que nos han dado patria y libertad auxiliados por los pueblos. La masa general de ellos les ha agradecido sus sacrificios, y han dado por bien empleadas las sumas que en VV. se han gastado, y las distinciones con que se ha condecorado su valor. Pero no han faltado algunos escritorsillos y representantes á quienes VV. les han puesto la República en elevado rango que se halla, que opinen y escriban en ella, que se les quite el fuero [...]. Ya se ve, muchos de estos señores ó no han estado aquí en nuestra sangrienta lucha, ó han estado bajo los auspicios del Sr. D. Fernando, ó eran entes insignificantes ahora cuatro años atrás, ó se enfermaron por no servir en el ejército, ó tienen ódios privados á los militares por resentimientos particulares, ó deseaban desaforar á los militares, porque se desaforáse á los eclesiásticos en ódio de su potestad. Han quedado burladas las esperanzas de unos y otros, pues se declaró el fuero militar, y yo estoy seguro, que en mejor época, los que han desembainado su espada para libertarnos, la pondrán á los pies de la soberanía nacional con el fuero, y se gloriarán de estar sometidos á la igualdad legal que debe reinar en las Repúblicas (El Chasqui Bogotano, 1826, p. 1).

Con respecto a los pronunciamientos efectuados frente a las cuestiones políticas que consideraban de su incumbencia, los militares tampoco callaron. A propósito de la Convención de Ocaña, que se realizó entre abril y junio de 1828, con el fin de reformar la Constitución política colombiana, no pocos militares hicieron públicas sus consideraciones, ya para defender el orden establecido o para apoyar la modificación de la constitución. Por un lado, y en una extensa carta dirigida a Santander, un grupo de militares expresó que, aunque ellos reconocían la subordinación, la no deliberación y la obediencia (que legal e institucionalmente debían tener frente al gobierno y frente a las demás autoridades estatales), no podían marginarse, ni dejar de expresar sus inquietudes y consideraciones frente a la crítica situación por la que atravesaba la república, ya que los partidismos, la crisis institucional y la conspiración que algunos individuos habían emprendido contra el gobierno legítimo y contra la

34 Ver La Bandera Tricolor (1826b, pp. 1-2). 
propia nación los obligaba, como ciudadanos antes que como militares, a pronunciarse enfáticamente contra el recelo con el que actuaban algunos diputados y contra todo aquel que pretendiera socavar la libertad y la institucionalidad establecida (Gaceta de Colombia, 1827). ${ }^{35}$

Por otro lado, y en una misiva aun más extensa que la que recibió Santander, otro grupo de militares también se pronunció para apoyar las iniciativas políticas que Bolívar pretendía fomentar en distintos campos de la administración pública y política. En carta dirigida al presidente de la Convención que iba a realizarse en Ocaña, adujeron que, en virtud de la crisis política e institucional en la que se hallaba Colombia, el país debía saber que los "militares libertadores" tenían derecho a emitir sus opiniones y a sugerir las medidas que debían tomarse para sortear la situación (Gaceta de Colombia, 1828). ${ }^{36}$

Así pues, y convencidos de la histórica función que, según ellos, debían cumplir en aras de afianzar un orden político e institucional que fuera congruente con el espíritu republicano, y empeñados en ganar la legitimidad y los apoyos públicos y políticos que sus respectivas causas requerían, tanto los antimilitaristas como los uniformados (actuaran de manera individual, grupal o corporativa), continuaron publicitando sus ideas, buscando siempre convalidarlas como si se tratara de asuntos de interés nacional y colectivo. Mientras que los primeros argumentaban que la proscripción política de los militares, la sustracción de las injustificadas prerrogativas que aquellos detentaban y la abolición del ejército eran irrecusables tareas que debían consumarse para bien de la república, de la libertad y de la igualdad que debía existir entre todos los neogranadinos; los segundos continuarían sosteniendo que la pervivencia de la fuerza armada era el medio fundamental para poder asegurar lo más preciado que se había logrado obtener tras tantos años de guerra y sacrificios: la independencia y la libertad.

Aunque el discurso de los antimilitaristas tuvo más difusión durante la década de los veinte del siglo XIX, las circunstancias en las que se halló

35 "Esposicion dirijida al supremo poder ejecutivo de la nación, por varios militares presentes en esta capital; en que manifiestan su adhesión al orden constitucional, y ofrecen de nuevo sus servicios para sostener la libertad e independencia". Carta fechada en Bogotá a 15 de febrero de 1827 y publicada en la Gaceta de Colombia (1827, pp. 2-3).

36 La misiva llevó por título "Por la patria i por Bolívar. Franca i respetuosa manifestación que hace de sus votos el bravo ejército del sur á la gran convención de Colombia”. Ver Gaceta de Colombia (1828, pp. 3-4). 
la república durante los últimos años de aquella parecieron coadyuvar para que los militares, por lo menos momentáneamente, vieran favorecidas sus expectativas. Luego de que fracasara la Convención de Ocaña, y a propósito de la instauración de las medidas de excepción que el "Libertador” promulgó en calidad de presidente de la república el 27 de agosto de 1828, los militares hallaron respaldo para su causa. A juicio de Bolívar, y dadas las supuestas arbitrariedades que los legisladores habían tomado en materia militar, el Ejecutivo debía asumir una función más activa en el ordenamiento institucional de la república y en el tratamiento de temas tan delicados como el de la cuestión militar. Investido de plenos poderes, apoyado por el Consejo de Estado y amparado con el título de "Libertador-Presidente", Bolívar impulsó un conjunto de medidas de gran impacto político e institucional en un momento en el que la Constitución política promulgada en 1821 virtualmente había expirado y en el que, según decían sus opositores, se había instaurado una dictadura encabezada por este y acolitada por los principales jefes y caudillos militares. ${ }^{37}$

Además de abolir la figura de los jueces letrados de primera instancia, sustraerle funciones a los alcaldes, depurar algunas de las cortes de justicia, alegando que algunos de sus ministros eran contrarios al espíritu y al interés públicos, el gobierno le sustrajo el tratamiento de las causas militares a la Alta Corte de Justicia y se lo entregó a la reconstituida Alta Corte Militar. Tomó varias medidas orientadas al fortalecimiento del fuero castrense, a la afirmación de la disciplina militar, al aumento y disminución, según su discrecionalidad, del pie de fuerza del ejército, a la promoción de ascensos militares y a la modificación del régimen electoral para que los uniformados pudieran ejercer el derecho al voto.

Reconocer y garantizar las reivindicaciones de los militares era, ciertamente, un compromiso político, institucional y personal que Bolívar había asumido con aquellos hombres que habían entregado su vida a la causa de la independencia. Sin embargo, y en tanto que los tiempos de la guerra de independencia ya se habían clausurado, en este nuevo contexto político sus opositores estaban decididos a no soportar el, según ellos, avieso régimen dictatorial que se había impuesto, ni a tolerar que conti-

37 Diversas y divergentes han sido las interpretaciones que, desde entonces y hasta nuestros días, se le ha dado a la decisión que tomó el general Bolívar con relación al gobierno de la república. Para un completo balance sobre el asunto, ver David Bushnell (2006) y Daniel Gutiérrez Ardila (2017, pp. 71-97). 
nuara privilegiando con ascensos, condecoraciones y nombramientos a los militares..$^{38}$

Aunque con menos intensidad, estos opositores continuaron expresando su animadversión. Sin embargo, no fueron sus arengas las que socavaron el régimen de gobierno establecido por Bolívar, ni las que definieron la suerte que tuvo el ejército colombiano. Tanto lo uno como lo otro se definiría como consecuencia de las diversas situaciones que se suscitaron en el país durante aquella época.

Tras las decisiones que tomó al amparo de las facultades que la ley le concedía, Bolívar tuvo que afrontar la feroz oposición que contra él levantaron sus adversarios, y debió lidiar con las sublevaciones dirigidas por algunos neogranadinos. En 1828, por ejemplo, los coroneles neogranadinos José Hilario López y José María Obando lideraron una insurrección en la provincia del Cauca, y a finales del año siguiente el general José María Córdova hizo lo propio en la provincia de Antioquia. Durante aquella misma época varias facciones políticas y militares venezolanas promovieron levantamientos armados en Caracas y Cumaná, y al poco tiempo los dirigentes y caudillos más reputados de ese país decidieron separar a Venezuela de la república de Colombia. ${ }^{39}$ El general José Antonio Páez asumió el mando civil y militar de la naciente república venezolana y persuadió a los generales, jefes y oficiales venezolanos que se hallaban comandando tropas en la Nueva Granada para que retornaran al seno de su patria, llevando consigo a los soldados y milicianos que tenían bajo su mando (Gaceta de Colombia, 1830b, pp. 1-3).

Sumado a lo anterior, y tras la penosa muerte del "Libertador", la república de Colombia llegó a su fin. De ahí en adelante, el destino del ejército y de los demás cuerpos armados que cada uno de estos países heredó, quedó en manos de sus respectivas autoridades y dependientes de las vicisitudes políticas por las que cada país atravesó durante las décadas siguientes. Cada quien encauzó, a su manera, el debate y las decisiones que se tomaron con respecto a los militares, pero lo hecho y lo dicho por los detractores del militarismo durante la década de los veinte no solo había sentado las bases a partir de las cuales se intentó desarticular

38 Así lo expresó, por ejemplo, Luis Vargas Tejada (1978), quien se atrevió a hacer explícitas las acusaciones contra el Libertador, llamándolo dictador y tirano e incitado a sus copartidarios para asesinarlo.

39 Ver José Gil Fortoul (1953, p. 682) y “Documentos que hicieron historia” (1989, pp. 354-366). 
el mentado espíritu militar o militarista que, según ellos, se había propagado en Colombia, sino que se constituyó en el referente discursivo, jurídico, político e ideológico a partir del cual se reencauzó y redefinió la cuestión militar en la Nueva Granada, Venezuela y Ecuador, después de que la república de Colombia quedó disuelta.

En el caso neogranadino, los promotores de la empresa antimilitarista continuaron fomentando la disminución del ejército y la abolición del fuero castrense, valiéndose de los discursos y argumentos que, con ese propósito, se habían elaborado y esgrimido durante los tiempos de la república de Colombia. Sin embargo, las vicisitudes políticas que acontecieron en el país durante las décadas siguientes, y especialmente las guerras civiles que se produjeron a raíz de la enconada disputa que sostuvieron las facciones partidistas que luego le darían vida a los partidos Liberal y Conservador hicieron que, aunque reducido, el ejército continuara existiendo. Persuadidos del favor que los uniformados podían prestarles para la defensa y consumación de sus respectivas causas, los dirigentes de los partidos, aliados con los principales y más reputados jefes militares, coincidieron en que esa fuerza debía seguir existiendo, pero sometida a la vigilancia y al control que aquellos fueron imponiendo.

El resultado tendió a ser el deseado. Insistiendo en la subordinación, obediencia y espíritu no deliberante que los militares debían asumir y mantener frente a las autoridades civiles del Estado, y vindicando el carácter civilista que debía tener la república neogranadina, los promotores de dicha empresa paulatinamente fueron acometiendo su proyecto: subordinar a los militares y erigirse como agentes rectores del orden institucional estableciendo, a su vez, un régimen político concordante, o mejor decir, diseñado a la medida de sus intereses y propósitos.

\section{Conclusiones}

Tal y como lo ha mostrado la copiosa producción historiográfica que se ha ocupado del tema, los efectos políticos, sociales, culturales e institucionales suscitados con la independencia de los países hispanoamericanos fueron múltiples. Uno de ellos, como hemos señalado en este artículo, fue el de la cuestión militar. El hecho de que la independencia se zanjara a través de la guerra, hizo que los dirigentes de ese proceso promovieran la formación de cuerpos armados de 
distinta naturaleza (ejércitos, milicias, marina y hasta guerrillas), con el fin de confrontar a sus adversarios.

Al término de ese proceso, la conformación de dichos cuerpos armados resultó tan efectiva como problemática, pues si bien es cierto que con ellos se logró consumar la independencia, se puso en evidencia que esos cuerpos también se habían convertido en una pesada carga fiscal, social, institucional y política para los nacientes Estados de la América hispánica. En tal virtud, la cuestión militar se convirtió en uno de los principales objetos de discusión pública y política.

En el caso colombiano, escenario en donde la guerra de independencia se libró con toda su crudeza y en donde la cantidad de hombres que integraron esos cuerpos osciló entre los 20000 y 30 000, el asunto derivó en la gestación de un rudo debate a efecto del cual legisladores, abogados, burócratas, publicistas, generadores de opinión pública y militares, pusieron en discusión pública cuál era el lugar y el papel que los militares debían desempeñar en el marco del nuevo orden político e institucional y, correlativamente, configurar, posicionar y proyectar un discurso civilista, antimilitarista, en virtud del cual se intentó orientar los destinos de la naciente república.

Al indagar sobre este asunto histórico, generalmente mencionado de manera superficial y a veces anecdótica en la historiografía política colombiana, se quiso identificar cómo, en el marco de las complejas relaciones de poder que tejieron con los uniformados, y en virtud de sus particulares intereses políticos, burocráticos e ideológicos, los detractores del mentado militarismo lograron elaborar y publicitar un sofisticado y persuasivo discurso civilista mediante el cual pretendieron proscribir, subordinar y acallar a los militares; y plantear algunas preguntas que, eventualmente, puedan servir para orientar nuevas reflexiones sobre lo que aconteció durante aquella experiencia política y sobre lo que eso significó en tiempos posteriores.

¿Hasta qué punto y de qué manera ese discurso civilista configurado y publicitado durante aquella época sirvió para que los cuerpos armados colombianos incorporaran, o se les inculcara, el mentado carácter civilista que los ha distinguido de sus pares latinoamericanos? A efecto de los hechos políticos que se sucedieron en Colombia durante la segunda mitad de la década de los veinte del siglo XIX ¿qué puede decirse respecto de la influencia que tuvo ese mentado militarismo en la disolución de la 
república de Colombia? Aunque son contextos y situaciones muy diferentes ¿qué interconexiones, y si acaso lecciones, pueden establecerse a partir de aquella experiencia histórica y de las experiencias que actualmente vivimos en Colombia a propósito de la anhelada, pero al parecer esquiva, culminación del conflicto armado, y de los legados militares que este ha dejado para la sociedad colombiana? Además de los costos humanitarios y económicos que este aparejó, los efectos derivados del sustancial aumento de la fuerza pública durante las últimas décadas, y que hoy son tema de debate público ¿no es, por ejemplo, un aspecto susceptible de ser analizado en perspectiva histórica y comparada volviendo la mirada hacia las experiencias vividas durante los primeros años de la república?

\section{Referencias}

Azuero, V., Bolivar, S. Valderrama Ortiz, C. y De Poмвo M. (2010). La propuesta federal. Bogotá: Universidad Nacional de Colombia.

Blanco Valdés, R. L. (1988). Rey, Cortes y fuerza armada en los orígenes de la España liberal, 18081823. Madrid: Institució Valenciana d'Estudis i Investigació/Siglo XXI editores.

Botero Montoya, L. H. (2014). La opinión pública en la formación de la ideología de la independencia en la Nueva Granada. Medellín: Universidad de Medellín.

Brito Figueroa, F. (1966). Historia Económica y Social de Venezuela. Una estructura para su estudio. Caracas: Universidad Central de Venezuela.

Brown, M. (2010). Aventureros, mercenarios y legiones extranjeras en la Independencia de las Gran Colombia. Medellín: Universidad Pedagógica y Tecnológica de Colombia/La Carreta Editores.

Buhsnell, D. (1985). El Régimen de Santander en la Gran Colombia. Bogotá: El Áncora Editores.

Bushnell, D. (2006). Ensayos de historia política de Colombia, siglos XIx y xx. Medellín: La Carreta Histórica.

Cacciatore, G. y Scocozza, A. (2010). El Gran Majadero de América. Simón Bolívar: pensamiento político y constitucional. Bogotá: Universitá Degli Studi di Salerno/ Universidad Católica de Colombia/Editorial Planeta.

Calderón, M. T. y Villamizar, C. (2009). Liberalismo. Colombia. En J. Fernández Sebastián (dir.), Diccionario político y social del mundo iberoamericano. La era de las revoluciones, 17501850 (pp. 771-781). Madrid: Fundación Carolina/Sociedad Estatal de Conmemoraciones Culturales/Centro de Estudios Políticos y Constitucionales.

Chaparro Rodríguez, J. C. (2010). Fuero y justicia penal militar en Colombia: debates y controversias. 1821-1829. Memoria y Sociedad, 14(29), 71-90. 
Chaparro Rodríguez, J. C. (2017). ¡Desmilitarizar las repúblicas! Ideario y proyecto político de los civilistas neogranadinos y venezolanos, 1810-1858. Bogotá: Universidad del Rosario.

Conde, J. J. (comp.). (1842). Proclamas de El Libertador Simón Bolivar. Caracas: Imprenta de El Venezolano.

Costeloe, M. P. (2010). La respuesta a la independencia. La España imperial y las revoluciones hispanoamericanas, 1810-1840. México: Fondo de Cultura Económica.

Documentos que hicieron historia, 1810-1989. Vida republicana de Venezuela (1989). Caracas: Ediciones Presidencia de la República.

Earle, R. A. (2014). España y la independencia de Colombia, 1810-1825. Bogotá: Universidad de los Andes.

Gil Fortoul, J. (1953). Historia Constitucional de Venezuela. Caracas: Ministerio de Educación.

González, F. (1975). Memorias. Medellín: Bolsilibros Bedout.

Gutiérrez Ardila, D. (2016). La restauración en la Nueva Granada, 1815-1819. Bogotá: Universidad Externado de Colombia.

Gutiérrez Ardila, D. (2017). El momento agónico de la república de Colombia. En I. Vanegas (ed.), El siglo diecinueve colombiano. Bogotá: Ediciones Plural.

Hensel Riveros, F. D. (2006). Vicios, virtudes y educación moral en la construcción de la república, 1821-1852. Bogotá. Universidad de los Andes.

Jaramillo Uribe, J. (2002). Bolívar. Escritos políticos. Bogotá: El Áncora Editores/Panamericana Editorial.

Kuethe, A. J. (1993). Reforma militar y sociedad en la Nueva Granada: 1773-1808. Bogotá: Banco de la República.

Leal Curier, C., Guerrero, C. y Plaza, E. (2009). Liberalismo. Venezuela. En J. Fernández Sebastián (dir.), Diccionario político y social del mundo iberoamericano. La era de las revoluciones, 17501850 (pp. 837-845). Madrid: Fundación Carolina/Sociedad Estatal de Conmemoraciones Culturales/Centro de Estudios Políticos y Constitucionales.

Llano Isaza, R. (1999). Centralismo y federalismo, 1810-1816. Bogotá: Banco de la República/El Áncora Editores, 1999.

Loaiza Cano, G. (2010). La prensa y la opinión pública en los inicios republicanos, 1808-1815. Medellín: Fundación Luis Antonio Restrepo Arango.

Lomné, G. (2009). De la República y otras repúblicas: la regeneración de un concepto. En J. Fernández Sebastián (dir.), Diccionario político y social del mundo iberoamericano. La era de las revoluciones, 1750-1850. Madrid: Fundación Carolina/Sociedad Estatal de Conmemoraciones Culturales/Centro de Estudios Políticos y Constitucionales.

Memoria del secretario de Estado y del despacho de guerra al primer congreso constitucional de Colombia en el año de 1823. (1823). Bogotá: Imprenta del Estado por Nicomedes Lora. 
Mercado, J. (1963). Campaña de Invasión del Teniente General don Pablo Morillo, 1815-1816. Bogotá: Biblioteca del Ejército.

Sábato, H. (2008). Horizontes republicanos en Iberoamérica. Una perspectiva de largo plazo. En B. Bragoni y S. E. Mata (comp.). Entre la Colonia y la República. Insurgencias, rebeliones y cultura política en América del Sur. Buenos Aires: Prometeo Libros.

Tejada Vargas, L. (1978). Recuerdo histórico. Bogotá: Academia Colombiana de Historia.

Thibaud, C. (2003). Repúblicas en armas: los ejércitos bolivarianos en la guerra de independencia en Colombia y Venezuela. Bogotá: Planeta/IEFA.

Thibaud, C. (2012). El soldado y el ciudadano en la guerra en la Nueva Granada. Ejército, milicia y libertad: una tensión inaugural. En F. Ortega y Y. A. Chicangana (eds.), Conceptos fundamentales de la cultura política de la Independencia. Bogotá: Universidad Nacional de Colombia/Centro de Estudios Sociales/University of Helsinki.

\section{Periódicos y revistas}

Correo de la ciudad de Bogotá (16 de mayo de 1822a). "Cuarta carta á D Candido Justo Veritas". N. 146 , pp. 1-2.

Correo de la ciudad de Bogotá (27 de junio de 1822b). "Sentimiento de un ciudadano a favor de la forma de gobierno de Colombia”. N.' 152, p. 1.

Correo de la ciudad de Bogotá (20 de marzo de 1823). N. 190 , p. 3.

Década: Miscelánea de Cartagena (19 de octubre de 1814). p. 6.

Diario Político de Santafé de Bogotá (28 de septiembre de 1810a). N. 11, pp. 1-2.

Diario Político de Santafé de Bogotá (9 de octubre de 1810b). ‥ 14, p. 1.

Diario Político de Santafé de Bogotá (21 de diciembre de 1810c). N. 34 , p. 1.

El Chasqui Bogotano (1826). N. ${ }^{\circ}$ 3, p. 1.

El Chasqui Bogotano (24 de mayo de 1827). N. 25 , p. 1.

El Eco de Antioquia (26 de mayo de 1822). "Sentimiento de un ciudadano a favor de la forma de gobierno de Colombia”. N. ${ }^{\circ}$ 4, pp. 3-4.

El Explorador (1814). ․․ 1, p. 5.

El Patriota (2 de marzo de 1823). N. 9 9, pp. 2-3.

El Zurriago (16 de diciembre de 1827). "Ramo militar". N. ${ }^{\circ}$ 1, p. 1.

El Zurriago (27 de enero de 1828). "Continúa el artículo Ramo Militar". ․․2, p. 1.

Gaceta de Colombia (15 de diciembre de 1822). N. ${ }^{\circ}$ 61, pp. 2-3.

Gaceta de Colombia (3 de abril de 1825). N. ${ }^{\circ} 181$, p. 1. 
Gaceta de Colombia (29 de abril de 1826a). ․․ 237, pp. 5-6.

Gaceta de Colombia (21 de mayo de 1826b). N. 240 , pp. 5-8.

Gaceta de Colombia (25 de junio de 1826c). N. 245, pp. 1-2.

Gaceta de Colombia (9 de julio de 1826d). N. 247 , p. 2.

Gaceta de Colombia (17 de junio de 1827). "Esposicion dirijida al supremo poder ejecutivo de la nación, por varios militares presentes en esta capital; en que manifiestan su adhesión al orden constitucional, y ofrecen de nuevo sus servicios para sostener la libertad e independencia". N. ${ }^{\circ} 296$, pp. 2-3.

Gaceta de Colombia (11 de mayo de 1828). "Por la patria i por Bolívar. Franca i respetuosa manifestación que hace de sus votos el bravo ejército del sur á la gran convención de Colombia”. N. 345 , pp. 3-4.

Gaceta de Colombia (13 de junio de 1830a). N. 469, p. 4.

Gaceta de Colombia (28 de junio de 1830b). N. ${ }^{\circ} 471$, pp. 1-3.

La Bagatela (28 de noviembre de 1811a). N. 22, pp. 1-2.

La Bagatela (15 de diciembre de 1811b). N. 25, pp. 1-2.

La Bagatela (8 de marzo de 1812). N. 36, pp. 1-2.

La Bandera Tricolor (16 de julio de 1826a). N.. 1, p. 3.

La Bandera Tricolor (24 de agosto de 1826b). "Holgazanería y holgazanes". N. 6, pp. 1-2. 